\title{
Analisis Beban Kerja PLLU Terhadap Pelayanan Lalu Lintas Penerbangan di Perum LPPNPI Cabang Denpasar
}

\author{
Dwi Lestary, Pangsa Rizkina Aswia, Ertha Andina L \\ Politeknik Penerbangan Indonesia Curug \\ e-mail: ${ }^{1}$ dwi.lestary@ppicurug.ac.id
}

\begin{abstract}
Abstrak
Penelitian ini bertujuan untuk mengetahui apakah terdapat hubungan yang negative yang artinya berbanding terbalik antara beban kerja yang di alami seorang ATC dengan pemberian pelayanan lalu lintas penerbangan. Dalam penelitian ini digunakan metode penelitian kuantitatif dengan dua analisis penelitian, pertama dengan menggunakan metode perhitungan regresi, pertama dilakukan untuk mendapatkan kesimpulan atas tingkat pengaruh variabel beban kerja terhadap variabel pemberian pelayanan lalu lintas penerbangan dan kedua, dengan menggunakan Nasa-TLX guna mengungkap lebih dalam terhadap tingkat beban kerja subyektif para controller yang meliputi tuntutan mental psikis, tuntutan fisik, tekanan waktu, kinerja, tingkat frustrasi, dan usaha kerja. Hasilnya didapatkan bahwa koefisien korelasi sebesar -0,628 dan koefisien determinasi sebesar $39 \%$, yang artinya bahwa pengaruh beban kerja personil ATC terhadap pemberian pelayanan lalu lintas penerbangan adalah sebesar 39\% dan selebihnya ditentukan oleh faktor-faktor lain yang tidak masuk dalam bagian penelitian.
\end{abstract}

Kata Kunci : Pemandu Lalu Lintas Udara, Beban Kerja

\section{PENDAHULUAN}

Bandar Udara Internasional I Gusti Ngurah Rai menurut fungsinya sebagai bandar udara yang terletak di pulau Bali. Hal ini menjadikan Bandar Udara Internasional ini terus mengalami peningkatan dalam jumlah pergerakan pesawat udara disetiap bulannya dan menjadi bandar udara tersibuk di Indonesia. Semakin meningkatnya jumlah pergerakan pesawat di suatu bandara bagi setiap maskapai penerbangan, maka bertambah pula jam kerja yang dimiliki oleh seorang ATC (Air Traffic Controller) untuk memenuhi kebutuhan masyarakat akan pelayanan jasa transportasi penerbangan (Cristi, P., \& Zaini, F., 2019)

(A.A.A Willyandari T D S.STr., 2018). Tidak jarang di temukan situasi dimana seorang ATC (Air Traffic Controller) melakukan tindakan yang tidak sesuai dengan apa yang seharusnya di lakukan oleh ATC (Air Traffic Controller) dalam pemanduan lalu lintas udara tersebut. Dampak dari hal itu tentu harus di sikapi dengan bijak dengan tujuan kestabilan fisik maupun psikis ATC (Air Traffic Controller) dapat di pertahankan. Untuk menuju profesionalisme yang di inginkan tentunya di butuhkan pembinaan mental psikologis 
yang tangguh agar terwujud kinerja yang optimal. Mental psikologis yang dimaksud diperuntukan bagi setiap invidu ATC (Air Traffic Controller). Pada saat traffic padat hal yang paling dibutuhkan seorang controller adalah berkonsentrasi tinggi menghadapi kondisi traffic. Terganggunya konsentrasi akan membuat turunnya kualitas pelayanan dan kesalahan mungkin sekali timbul, yang akibatnya akan membahayakan keselamatan penerbangan. Hal ini disebabkan karena terlalu beratnya beban kerja yang menjadi tanggung jawab dari personil ATC di Unit Aerodrome Control Tower maupun Approach Control unit Di wilayah tanggung jawab udara yang harus dipandunya menambah kepadatan dan kerumitan Situasi Traffic daerah tersebut. Tujuan dari penelitian ini adalah melakukan analisis terhadap beban kerja personil ATC yang nantinya akan menjadi bahan pertimbangan atau rujukan dalam penentuan standar dan untuk melihat pengaruh beban kerja tersebut dalam kualitas standar pelayanan seperti yang tercantum di Human Factor Digest 8 Chapter 3 "Workload may be generated by different parameters which cannot easily be aggregated, including the number of aircraft and the complexity of the traffic situation, which is not a simple function of aircraft numbers".

\section{METODE}

Penelitian ini dilaksanakan dalam enam bulan terhitung maret sampai dengan september 2021 di bandar udara I Gusti Ngurah Rai-Denpasar. Dalam penelitian ini, penulis menggunakan metode penelitian kuantitatif dengan penelitian ini menggunakan metode kuantitatif dengan dua analisis penelitian Pertama dengan menggunakan metode perhitungan regresi, yang dilakukan untuk mendapatkan kesimpulan atas tingkat pengaruh variabel beban kerja terhadap variabel pemberian pelayanan lalu lintas penerbangan. Analisis kedua dengan menggunakan Nasa-TLX guna mengungkap lebih dalam terhadap tingkat beban kerja subyektif para controller yang meliputi tuntutan mental psikis, tuntutan fisik, tekanan waktu, kinerja, tingkat frustrasi, dan usaha kerja. Dengan metode ini, penulis dapat menggambarkan secara jelas, tidak dimanipulasi, dan apa adanya tentang pengaruh beban kerja personel ATC terhadap pemberian pelayanan lalu lintas penerbangan sehingga dapat diperoleh data yang bisa dijadikan studi kasus sebagai bahan analisis. Dalam melakukan penelitian, penulis mengukur analisis data terhadap variabel-variabel yang ada.

\section{HASIL DAN PEMBAHASAN}

Dari hasil penelitian di lapangan maka dapat diperoleh data- data sesuai dengan fakta yang ada, pengumpulan data yang berdasarkan pada data primer, data sekunder dan penyebaran daftar pertanyaan dalam bentuk kuisioner yang dilakukan pada populasi sebanyak 62 orang. Agar data kuisioner yang diperoleh sesuai dengan yang dibutuhkan, maka daftar pertanyaan tersebut telah dirancang agar memenuhi beberapa kriteria sehingga mendapatkan jawaban dari 53 responden.

Untuk mengukur validitas maka syarat minimum yang dianggap memenuhi syarat adalah apabila nilai koefisien korelasi (ri) hasil perhitungannya bernilai positif, dan hasil perhitungan nilai koefisien korelasinya harus lebih besar dari nilai koefisien dari tabel ( $\mathrm{r}$ hitung $>\mathrm{r}$ tabel) (D.Amalia, 2019). Jika nilai koefisien korelasi lebih kecil dari nilai tabel dan bernilai negatif maka butir pernyataan tersebut tidak valid dan harus dihilangkan untuk analisis berikutnya. (Jonathan Sarwono, 2013). Dalam tahap ini penulis menggunakan bantuan perangkat Data Analyze dari program SPSS23 untuk mempermudah perhitungan koefisien korelasi tiap-tiap skor butir pertanyaan dengan skor total, data perhitungan. Berikut 
adalah data hasil uji validitas instrument variabel Y.

Tabel 1. Uji Validitas

\begin{tabular}{|l|c|c|l|}
\hline Item & R Hitung & $\begin{array}{c}\text { R } \\
\text { Tabel }\end{array}$ & Keterangan \\
\hline P1 & 0.534919 & 0.2656 & Valid \\
\hline P2 & 0.524336 & 0.2656 & Valid \\
\hline P3 & 0.287802 & 0.2656 & Valid \\
\hline P4 & 0.543839 & 0.2656 & Valid \\
\hline P5 & 0.437704 & 0.2656 & Valid \\
\hline P6 & 0.608663 & 0.2656 & Valid \\
\hline P7 & 0.369935 & 0.2656 & Valid \\
\hline P8 & 0.470716 & 0.2656 & Valid \\
\hline P9 & 0.334038 & 0.2656 & Valid \\
\hline P10 & 0.612184 & 0.2656 & Valid \\
\hline
\end{tabular}

Tabel 2. Hasil Kuesioner

\begin{tabular}{|c|c|c|c|c|c|c|c|c|c|c|c|}
\hline No & $\mathrm{Y} 1$ & $\mathrm{Y} 2$ & $\mathrm{Y3}$ & $\mathrm{Y} 4$ & $\mathrm{Y} 5$ & $\mathrm{Y} 6$ & $\mathrm{Y} 7$ & $\mathrm{Y} 8$ & $\mathrm{Y} 9$ & $\mathrm{Y} 10$ & TOTAL \\
\hline 1 & 4 & 3 & 3 & 5 & 4 & 4 & 4 & 5 & 5 & 5 & 42 \\
\hline 2 & 3 & 3 & 3 & 4 & 4 & 4 & 3 & 4 & 4 & 4 & 36 \\
\hline 3 & 4 & 4 & 4 & 5 & 4 & 4 & 4 & 5 & 5 & 5 & 44 \\
\hline 4 & 4 & 4 & 4 & 5 & 5 & 4 & 4 & 5 & 5 & 5 & 45 \\
\hline 5 & 4 & 2 & 4 & 5 & 4 & 4 & 4 & 5 & 5 & 5 & 42 \\
\hline 6 & 4 & 3 & 4 & 5 & 4 & 4 & 4 & 5 & 5 & 5 & 43 \\
\hline 7 & 4 & 4 & 4 & 4 & 4 & 4 & 4 & 5 & 5 & 4 & 42 \\
\hline 8 & 4 & 4 & 4 & 5 & 4 & 4 & 4 & 5 & 5 & 4 & 43 \\
\hline 9 & 3 & 3 & 4 & 4 & 4 & 3 & 3 & 4 & 4 & 3 & 35 \\
\hline 10 & 4 & 4 & 3 & 5 & 4 & 3 & 3 & 5 & 5 & 5 & 41 \\
\hline 11 & 4 & 4 & 4 & 5 & 5 & 4 & 4 & 5 & 5 & 5 & 45 \\
\hline 12 & 4 & 3 & 4 & 4 & 3 & 4 & 4 & 4 & 4 & 4 & 38 \\
\hline 13 & 4 & 4 & 4 & 5 & 4 & 4 & 4 & 5 & 5 & 5 & 44 \\
\hline 14 & 4 & 5 & 4 & 5 & 4 & 4 & 5 & 4 & 5 & 4 & 44 \\
\hline
\end{tabular}

\begin{tabular}{|c|c|c|c|c|c|c|c|c|c|c|c|}
\hline 15 & 5 & 4 & 4 & 5 & 4 & 5 & 4 & 5 & 5 & 5 & 46 \\
\hline 16 & 5 & 4 & 4 & 5 & 4 & 5 & 4 & 5 & 5 & 5 & 46 \\
\hline 17 & 3 & 4 & 3 & 4 & 5 & 4 & 4 & 5 & 4 & 4 & 40 \\
\hline 18 & 3 & 4 & 3 & 4 & 5 & 4 & 4 & 5 & 4 & 4 & 40 \\
\hline 19 & 4 & 4 & 3 & 4 & 5 & 4 & 5 & 4 & 5 & 4 & 42 \\
\hline 20 & 4 & 4 & 3 & 4 & 5 & 4 & 5 & 4 & 4 & 4 & 41 \\
\hline 21 & 4 & 3 & 4 & 4 & 3 & 4 & 4 & 5 & 5 & 4 & 40 \\
\hline 22 & 3 & 4 & 3 & 4 & 5 & 4 & 4 & 5 & 4 & 4 & 40 \\
\hline 23 & 5 & 4 & 4 & 5 & 4 & 2 & 4 & 5 & 4 & 5 & 42 \\
\hline 24 & 4 & 3 & 4 & 4 & 2 & 3 & 4 & 3 & 5 & 4 & 36 \\
\hline 25 & 3 & 4 & 4 & 5 & 4 & 3 & 4 & 3 & 5 & 4 & 39 \\
\hline 26 & 3 & 4 & 4 & 5 & 4 & 3 & 4 & 3 & 5 & 4 & 39 \\
\hline 27 & 4 & 4 & 4 & 4 & 4 & 4 & 4 & 4 & 4 & 4 & 40 \\
\hline 28 & 3 & 2 & 5 & 4 & 4 & 3 & 3 & 5 & 5 & 4 & 38 \\
\hline 29 & 4 & 2 & 3 & 5 & 4 & 4 & 4 & 4 & 4 & 4 & 38 \\
\hline 30 & 4 & 4 & 4 & 5 & 5 & 4 & 4 & 5 & 4 & 5 & 44 \\
\hline 31 & 3 & 3 & 4 & 4 & 4 & 3 & 4 & 4 & 5 & 4 & 38 \\
\hline 32 & 4 & 4 & 4 & 4 & 4 & 4 & 4 & 4 & 5 & 4 & 41 \\
\hline 33 & 4 & 4 & 4 & 5 & 4 & 5 & 5 & 4 & 5 & 4 & 44 \\
\hline 34 & 4 & 4 & 4 & 4 & 4 & 4 & 4 & 4 & 5 & 4 & 41 \\
\hline 35 & 4 & 4 & 4 & 4 & 4 & 5 & 4 & 5 & 5 & 5 & 44 \\
\hline 36 & 4 & 4 & 4 & 4 & 4 & 4 & 4 & 4 & 5 & 4 & 41 \\
\hline 37 & 4 & 4 & 4 & 4 & 4 & 4 & 4 & 4 & 5 & 4 & 41 \\
\hline 38 & 4 & 5 & 4 & 5 & 4 & 5 & 4 & 5 & 5 & 5 & 46 \\
\hline 39 & 4 & 4 & 4 & 4 & 4 & 4 & 4 & 4 & 5 & 4 & 41 \\
\hline 40 & 5 & 5 & 5 & 4 & 4 & 4 & 4 & 4 & 5 & 5 & 45 \\
\hline 41 & 4 & 2 & 3 & 5 & 3 & 3 & 3 & 5 & 5 & 5 & 38 \\
\hline 42 & 2 & 5 & 4 & 4 & 4 & 4 & 4 & 4 & 4 & 4 & 39 \\
\hline 43 & 4 & 4 & 4 & 5 & 5 & 4 & 4 & 4 & 5 & 4 & 43 \\
\hline 44 & 3 & 4 & 4 & 4 & 4 & 4 & 4 & 4 & 4 & 4 & 39 \\
\hline 45 & 5 & 2 & 3 & 4 & 2 & 4 & 4 & 5 & 5 & 4 & 38 \\
\hline 46 & 4 & 4 & 4 & 5 & 4 & 3 & 5 & 4 & 4 & 3 & 40 \\
\hline 47 & 4 & 2 & 4 & 4 & 3 & 4 & 5 & 4 & 5 & 4 & 39 \\
\hline 48 & 4 & 3 & 4 & 4 & 5 & 5 & 4 & 4 & 5 & 4 & 42 \\
\hline
\end{tabular}




\begin{tabular}{|l|l|l|l|l|l|l|l|l|l|l|l|}
\hline 49 & 4 & 4 & 5 & 5 & 4 & 5 & 5 & 5 & 4 & 4 & 45 \\
\hline 50 & 4 & 4 & 4 & 5 & 4 & 4 & 5 & 4 & 5 & 4 & 43 \\
\hline
\end{tabular}

Pengujian reliabilitas instrumen dalam penelitian ini menggunakan Teknik Cronbanch's Alpha dengan ketentuan bahwa satu butir pernyataan mempunyai reliabilitas, nilai Cronbach's Alpha positif tidak boleh negattif, serta nilai hasil perhitungan sama atau lebih besar dari yaitu 0,6 (Jonathan Sarwono, 2013).

Berdasarkan rumus croanch's alpha tersebut didapat realibilitas variabel $\mathrm{Y}$ yaitu 0,615 yang berdasarkan tabel croanch's alpha dapat diartikan variabel $\mathrm{Y}$ sangat reliabel.

\begin{tabular}{|l|l|l|l|l|l|l|l|l|l|l|l|}
\hline 51 & 4 & 4 & 4 & 4 & 4 & 3 & 4 & 4 & 5 & 4 & 40 \\
\hline
\end{tabular}

Metode analisis data yang digunakan peneliti adalah teknik statistik korelasi, determinasi dan uji hipotesis dengan $t$ test. Sebelum melakukan analisis, suatu data perlu dilakukan uji normalitas yang digunakan untuk mengetahui bentuk persebaran/distribusi data tersebut (Sugiyono:2015). Uji Normalitas dengan dua data dapat dilakukan menggunakan teknik Kolmogorov Smirnov 2 - Tailed. Pada penelitian ini peneliti menggunakan aplikasi SPSS untuk melakukan perhitungan statistik. Berikut adalah hasil uji normalitas kolmogorov smirnov menggunakan program SPSS.

Tabel 3. One-Sample Kolmogorov-Smirnov Test

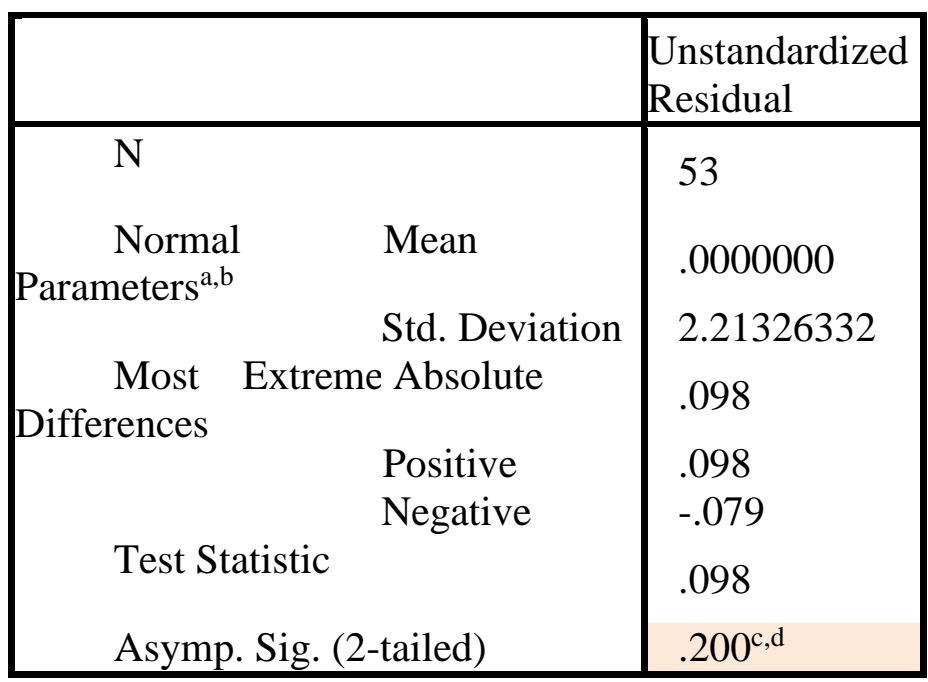

Berdasarkan tabel output SPSS tersebut, dapat dilihat nilai Asymp.Sig.(2tailed) pada Unstandardized Residual adalah .200 yang artinya 0,2, maka $\mathrm{H}_{1}$ diterima. Sesuai dengan dasar pengambilan keputusan dalam uji normalitas Kolmogorov-Smirnov diatas, dapat disimpulkan bahwa data berdistribusi normal. Dengan demikian, persyaratan uji normalitas sudah terpenuhi. Hasil analisis dari korelasi adalah koefisien korelasi yang menunjukkan keuatan atau kelemahan dari suatu hubungan. Nilai koefisien korelasi ini akan berada pada kisaran angka minus satu (-1) sampai plus satu (+1). Koefisien korelasi minus menunjukkan hubungan yang terbalik, pengaruh yang terjadi adalah pengaruh negative. Dari data pada lampiran dapat diketahui derajat hubungan antara beban kerja dan pemberian pelayanan dengan menggunakan teknik 
korelasi sederhana melalui perhitungan yaitu $-0,628$.

Tabel 4. Tingkat Korelasi

\begin{tabular}{|c|c|c|c|c|}
\hline & & & beban kerja & pelayanan \\
\hline \multirow[t]{2}{*}{$\begin{array}{l}\text { Spearman's } \\
\text { rho }\end{array}$} & beban kerja & $\begin{array}{c}\text { Correlation } \\
\text { Coefficient } \\
\text { Sig. (2-tailed) } \\
\text { N }\end{array}$ & $\begin{array}{c}1.000 \\
\cdot \\
53\end{array}$ & $\begin{array}{c}-.628^{*} \\
.000 \\
53\end{array}$ \\
\hline & pelayanan & $\begin{array}{c}\text { Correlation } \\
\text { Coefficient } \\
\text { Sig. (2-tailed) } \\
\mathrm{N}\end{array}$ & $\begin{array}{c}-.628^{* *} \\
.000 \\
53\end{array}$ & $\begin{array}{c}1.000 \\
\cdot \\
53\end{array}$ \\
\hline
\end{tabular}

**. Correlation is significant at the 0.01 level (2-tailed).

Selanjutnya untuk mem-buktikan adanya pengaruh antara variabel $\mathrm{x}$ dan variabel y. Maka peneliti melakukan analisis dengan menggunakan Koefisien Determinasi. Sedangkan untuk mengetahui seberapa besar kuat hubungan tersebut dapat diketahui melalui koefisien determinasi $\left(\mathbf{r}^{2}\right)$, yaitu $\mathbf{r}^{2}=\mathbf{0 , 3 9 4}$. Hal ini berarti bahwa pemberian pelaynanan pemandu lalu lintas udara 39\% ditentukan oleh besarnya beban kerja yang diperoleh dan $61 \%$ ditentukan oleh faktor lain, seperti kondisi peralatan,komunikasi, tingkat stress, koordinasi dan lain-lain.

Maka diketahui $t_{\text {-tabel }}=2.008$, maka dapat diambil kesimpulan sebagai berikut Nilai $t_{\text {hitung }}=\mathbf{- 5 , 5 1 3}<\mathbf{- 2 . 0 0 8}\left(\mathrm{t}_{\text {-tabel }}\right)$, maka dapat diambil kesimpulan bahwa Ho ditolak dan Ha diterima, yang berarti bahwa terdapat Pengaruh negatif yang signifikan antar beban kerja terhadap pemberian pelayanan pemandu lalu lintas penerbangan.

\section{KESIMPULAN}

Berdasarkan penyajian dan analisa hasil penelitian secara empiris dapat dinyatakan berpengaruh signifikan, hal ini terbukti dari hasil analisis data menggunakan uji korelasi diketahui hasilnya sebesar 0,394 yang dapat disimpulkan bahwa terdapat determinasi (pengaruhnya) sebesar 39\%. Dan 61\% di pengaruhi oleh faktor lain yang tidak di teliti.

\section{DAFTAR PUSTAKA}

Aminarno Budi Pradana, Drs, S.Si.T, MM,. (2019). Metode Penelitian Ilmiah Sekolah Tinggi Penerbangan Indonesia, Curug-Tangerang, 2019.

Amalia, D. (2019). Promoting Just Culture For Enhancing Safety Culture In Aerodrome Airside Operation. International Journal of Scientific \& Technology Research, 8(10), 260266.

A.A.A Willyandari T D S.STr. (2018). Pengaruh kepadatan Traffic dalam terminal South terhadap beban kerja di Approach Control Unit (APP) Jakarta Air traffic Service Center, DIV tugas akhir, Politeknik Penerbangan Indonesia. 
Cristi, P., \& Zaini, F. (2019). PENGARUH JUMLAH TRAFFIC TERHADAP BEBAN KERJA AIR TRAFFIC CONTROLLER (ATC) DI JAKARTA LOWER CONTROL NORTH. Langit Biru: Jurnal Ilmiah Aviasi, 12(3), 91-100.

Nugraha, W., \& Amalia, D. (2021). Covid19 and Implementation of Airport Health and Safety Procedures: The Safety Culture Perception. Syntax Literate; Jurnal Ilmiah Indonesia, 6(4), 2070-2082

Wahyu dwi nugroho S.STr. (2019). Analisis pengaruh beban kerja terhadap tingkat stress personel Approach unit di Makasar Air traffic Service Center, DIV tugas akhir, Politeknik Penerbangan Indonesia.

International Civil Aviation Organization. (2016). Doc. 4444, Air Traffic Management, $16^{\text {th }}$ Edition, Montreal: Secretary General.

Human Factor Digest No.8 ICAO Circular, Human Factors in Air Traffic Control 241-AN/145, ICAO, Montreal, .Canada.

ICAO Circular 247-AN/145, Human Factors Digest No.8, Human Factors in Air Traffic Control. Montreal, .Canada

Doc.9426-AN/924, Air Traffic Services Planning Manual Part IV, Section I Organization and Administration, Chapter 2 Personnel Requirement, Recruitment and Progression.

(PT.DBM) Muhammad Arasyandi, Arfan Bakhtiar ANALISA BEBAN KERJA MENTAL DENGAN METODE NASA TLX PADA OPERATOR KARGO DI PT. DHARMA BANDAR MANDALA Program Studi Teknik Industri, Fakultas Teknik, Universitas Diponegoro, Jl. Prof. Soedarto, SH, Kampus Undip Tembalang, Semarang, Indonesia

Air Traffic Service, Annex 11, Chapter 2, Point 2.2, 2016 tentang ATS Safety Management

Sugiyono, Prof, Dr. (2014). Metode Penelitian Pendidikan Pendekatan Kuantitatif, Kualitatif Dan $R \& D$. Bandung : Alfabeta.

Syofian Siregar. (2014). Statistik Parametrik Untuk Penelitan Kuantitatif, Jakarta: PT Bumi Aksara. 